\title{
Pengelompokkan Data Pembelian Tinta Dengan Menggunakan Metode K-Means
}

\author{
Susliansyah"1, Heny Sumarno², Hendro Priyono ${ }^{3}$, Noer Hikmah ${ }^{4}$ \\ Sistem Informasi, Universitas Bina Sarana Informatika \\ Jl. Kamal Raya No. 18, Ringroad Barat, Cengkareng, Jakarta Barat \\ Jl. Margonda Raya 100 Pondok Cina Depok \\ 021-54376398, 021-78881112 \\ susliansyah.slx@bsi.ac.id,heny_nyno@yahoo.com,hendrop250@gmail.com, \\ Noer.nhh@bsi.ac.id
}

\begin{abstract}
PT. Mayer Indah Indonesia is engaged in the production of goods, where the most important part to prepare the needs for production needs is the purchasing department, but in the purchasing section it is difficult to determine which items must be bought a lot, are and few in meeting the demand requirements of each part because of the needs goods for production are very unpredictable, eventually causing some goods demand not to be fulfilled because the goods are out of stock. To solve the problems experienced by the purchasing part, datamining using clustering algorithm is $k$-means method, where the initial stages determine the centroid randomly and do the first iteration calculation and determine the new centroid from the first iteration, then the second iteration calculation is done, because the results of the first and second iterations in the smallest layout of the three groups, the calculation stops. The results obtained by using the ink purchase data seen from the three attributes of incoming goods, items purchased and stock of goods, making it easier and help the purchasing department in classifying items that must be purchased a lot, medium and little.
\end{abstract}

Keywords: Datamining, Clustering, K-means, Purchasing

\begin{abstract}
Abstrak
Perusahaan PT. Mayer Indah Indonesia bergerak dibidang produksi barang, dimana bagian yang paling sangat penting untuk menyiapkan kebutuhan untuk keperluan produksi adalah bagian pembelian, tetapi dibagian pembelian mengalami kesulitan untuk menentukan barang mana yang harus dibeli banyak, sedang dan sedikit dalam memenuhi kebutuhan permintaan dari setiap bagian dikarenakan kebutuhan barang untuk produksi sangat tidak bisa diprediksi, akhirnya menyebabkan beberapa permintaan barang tidak terpenuhi dikarenakan persediaan barang habis. Untuk menyelesaikan permasalahan yang dialami bagian pembelian digunakan datamining dengan algoritma clustering yaitu metode k-means, dimana tahapan awalnya menentukan centroid secara acak dan melakukan perhitungan iterasi pertama serta menentukan centroid baru dari iterasi pertama, selanjutnya dilakukan perhitungan iterasi kedua, dikarenakan hasil iterasinya pertama dan kedua pada tata letak jarak yang paling kecil pada tiga pengelompokkan sama, maka perhitungan berhenti. Hasil yang diperoleh dengan menggunakan data pembelian tinta yang dilihat dari tiga attribut barang yang masuk, barang yang dibeli dan stok barang, sehingga memudahkan dan membantu bagian pembelian dalam mengelompokkan barang yang harus dibeli banyak, sedang dan sedikit.
\end{abstract}

Kata kunci: Datamining, Clustering, K-means, Pembelian

\section{PENDAHULUAN}

PT. Mayer Indah Indonesia bergerak dibidang tekstil yang berfokus pada pembuatan Rachel, tali, dan sulaman. Adapun jenis produk mulai dari renda Rachel berkualitas tinggi (renda sempit/kaku, renda allover/brokat, 
dan renda tirai), bordir yang mencakup trimming dan allover lace, dan renda mengepang. Saat ini memperluas pasar secara global ke Amerika, Eropa dan Timur Tengah dan mencari agen tekstil profesional untuk mendukung memasuki pasar baru. Pada PT. Mayer Indah Indonesia bergerak dibidang produksi barang, dimana bagian yang paling sangat penting untuk menyiapkan kebutuhan untuk keperluan produksi adalah bagian pembelian.

Bagian pembelian dalam menganalisa persediaan barang yang harus dibeli masih menggunakan sistem konvensional, sehingga mengalami kesulitan untuk menentukan barang mana yang harus dibeli banyak, sedang dan sedikit dalam memenuhi kebutuhan permintaan dari setiap bagianbagian dikarenakan kebutuhan barang untuk produksi sangat tidak bisa diprediksi. akhirnya menyebabkan beberapa permintaan barang tidak terpenuhi dikarenakan persediaan barang habis. Dalam penyelesaian permasalahan diatas, maka diperlukan sebuah solusi untuk dapat menentukan pembelian barang dengan tepat, yaitu dengan menggunkan metode K-means. Adapun penelitian yang terkait dengan tujuan untuk memperkuat permasalahan diatas sebagai berikut: (1) Pada swalayan Fadhilla dalam mengelola data penjulannya masih dilakukan dengan cara manual dan juga masih tidak bisa mengelompokkan data barang yang laris dan yang tidak laris dijual. Sehingga mengalami kesulitan yaitu seringnya kekurangan stok barang yang laku dikarenakan penjualan sangat tinggi. (2) Selain itu menumpuknya barang yang tidak laku di gudang dikarenakan penjualan sangat rendah. Dalam penyelesaian permasalahan ini, digunakan penerapan algoritma clustering dengan metode K-means [1].

CV Terang Jaya merupakan perusahaan dibidang Otomotif yang fokus pada melayani pembelian dan penjualan barang sparepart mobil serta memberikan service bermacam-macam merek mobil. Akan tetapi CV Terang Jaya kurang dalam hal pemantauan barang yang dijual, barang-barang apa saja yang diperlukan oleh konsumen dan dalam penyimpanan data juga kurang efektif. Untuk mengatasi permasalahan tersebut maka digunakan penerapan Clustering dengan menggunakan metode K-Means [4]. Permasalahan yang sering terjadi pada online shop dikarenakan online shop mengalami kesulitan pada saat menentukan stok minimum pada tiap barang yang harus dipenuhi berdasarkan keinginan konsumen. Untuk mengatasi permasalahan yang dialami saat ini, maka dibutuhkan sebuah metode sehingga dapat menentukan barang mana yang harus di stok banyak, sedang atau bahkan sedikit agar tidak lagi mengalami kekurangan atau bahkan kelebihan dalam pemenuhan stok barang tertentu, metode yang digunakan pada penelitian ini adalah metode K-Means [2].

\section{METODOLOGI PENELITIAN}

\subsection{Pengumpulan Data}

Untuk memperoleh data yang diperlukan dalam penelitian ini, maka dilakukan dengan cara: 
1. Observasi

Melihat proses bagian pembelian dalam mencatat semua barang yang dibeli sampai nanti ada permintaan barang tersebut disetiap bagian.

2. Wawancara

Melakukan wawancara dengan kepala bagian dan asisten yaitu dengan ibu Lestari dan Ibu Maya yang berkaitan dengan data-data barang yang dibeli selama 6 bulan.

\subsection{Datamining}

Berbagai ragam tentang pendefinisian data mining, meliputi sebagai berikut [3]:

a. Penguraian (yang tidak sederhana) dari sekumpulan data menjadi informasi yang memiliki potensi secara implisit (tidak nyata/jelas) yang sebelumnya tidak diketahui.

b. Penggalian dan analisis, dengan menggunakan piranti otomatis atau semi otomatis, dari sejumlah besar data yang bertujuan untuk menemukan pola yang memiliki arti.

c. Data mining juga merupakan bagian dari knowledge discovery dalam database (KDD).

\subsection{Clustering}

Clustering adalah sebuah proses untuk mengelompokkan data ke dalam beberapa cluster atau kelompok sehingga data dalam satu cluster memiliki tingkat kemiripan yang maksimum dan data antar cluster memiliki kemiripan yang minimum [5]. Metode clustering juga harus dapat mengukur kemampuannya sendiri dalam usaha untuk menemukan suatu pola tersembunyi pada adata yang sedang diteliti. Terdapat berbagai metode yang dapat digunakan untuk mengukur nilai kesamaan antar objek-objek yang dibandingkan. Salah satunya ialah dengan Weighted Euclidean Distance.

Euclidean Distance menghitung jarak dua buah point dengan mengetahui nilai masing-masing atribut pada kedua poin tersebut. Berikut formula yang digunakan untuk menghitung jarak dengan Euclidean Distance:

Distance $(p, q)=\left(\sum_{k}^{n} \mu k|P k-q k| r\right) 1 / \mathrm{r}$

Keterangan:

$\mathrm{N}=$ Jumlah record data

$\mathrm{K}=$ Urutan field data

$\mathrm{r} \quad=2$

$\mu \mathrm{k} \quad=$ Bobot field yang diberikan $u$ ser

Jarak adalah pendekatan yang umum dipakai untuk menetukan kesamaan atau ketidaksamaan dua vektor fitur yang dinyatakan dengan ranking. Apabila nilai ranking yang dihasilkan semakin kecil nilainya maka semakin dekat/tinggi kesamaan antara kedua vektor tersebut. Teknik pengukuran jarak dengan metode Euclidean menjadi salah satu metode yang 
paling umun digunakan. Pengukuran jarak dengan meotde Euclidean dapat dituliskan dengan persamaan berikut:

$$
j\left(v_{1}, v_{2}\right)=\sqrt{\sum_{k=1}^{N}\left(v_{1}(k)-v_{2}(k)\right)^{2}}
$$

\subsection{Algoritma K-means}

Merupakan salah satu algoritma klastering dengan metode partisi (partitioning method) yang berbasis titik pusat (centroid). Algoritma K-Means dalam penerapannya memerlukan tiga parameter yang seluruhnya ditentukan pengguna yaitu jumlah cluster $\mathrm{k}$, inisialisasi klaster, dan jarak sistem. Biasanya K-Means dijalankan secara independen dengan inisialisasi yang berbeda menghasilkan cluster akhir yang berbeda karena algoritma ini secara prinsip hanya mengelompokkan data menuju local minimal [5]. Tahapan-tahapan dalam algoritma K-Means sebagai berikut [5]:

1. Tentukan berapa banyak cluster $\mathrm{k}$ dari dataset yang akan dibagi.

2. Tetapkan secara acak data k menjadi pusat awal lokasi klaster.

3. Untuk masing-masing data, temukan pusat cluster terdekat. Dengan demikian berarti masing-masing pusat cluster memiliki sebuah subset dari dataset, sehingga mewakili bagian dari dataset. Oleh karena itu, telah terbentuk cluster $\mathrm{k}: \mathrm{C} 1, \mathrm{C} 2, \mathrm{C} 3, \ldots \ldots . ., \mathrm{Ck}$.

4. Untuk masing-masing cluster $\mathrm{k}$, temukan pusat luasan klaster, dan perbarui lokasi dari masing-masing pusat cluster ke nilai baru dari pusat luasan.

5. Ulangi langkah ke-3 dan ke-5 hingga data-data pada tiap cluster menjadi terpusat atau selesai.

\section{HASIL DAN PEMBAHASAN}

\subsection{Pengelompokkan Data Pembelian}

Data pembelian tinta selama 6 bulan yang diproses pada tiga kelompok yaitu barang paling banyak keluar, sedang dan sedikit berdasarkan dari attribut barang masuk, barang keluar dan Stok barang. Pada penelitian ini sampel yang diambil sebanyak 42 data pada PT. Mayer Indah Indonesia.

Tabel.1 Data Pembelian Tinta PT. Mayer Indah Indonesia

\begin{tabular}{|l|l|c|c|c|}
\hline KdBrg & Nama Barang & Barang Masuk & Barang Keluar & Stok Barang \\
\hline T1 & TINTA SNOWMAN 70 BIRU & 100 & 50 & 50 \\
\hline T2 & TINTA SNOWMAN 70 HITAM & 75 & 22 & 53 \\
\hline T3 & TINTA ARTLINE 500 HITAM & 80 & 30 & 50 \\
\hline T4 & TINTA ARTLINE 500 BIRU & $\mathbf{1 2 2}$ & $\mathbf{7 0}$ & $\mathbf{5 2}$ \\
\hline T5 & TINTA ARTLINE 500 MERAH & 121 & 45 & 76 \\
\hline T6 & TINTA STEMPEL BIRU & 150 & 100 & 50 \\
\hline T7 & TINTA STEMPEL HITAM & 124 & 60 & 64 \\
\hline T8 & TINTA STEMPEL MERAH & 143 & 80 & 63 \\
\hline T9 & TINTA CANON BCI-24 BLACK & 110 & 55 & 55 \\
\hline
\end{tabular}


Jurnal Sains Komputer \& Informatika (J-SAKTI)

Volume 3 Nomor 2 September 2019, pp. 381-392

ISSN:2548-9771/EISSN:2549-7200

http://tunasbangsa.ac.id/ejurnal/index.php/jsakti

\begin{tabular}{|c|c|c|c|c|}
\hline KdBrg & Nama Barang & Barang Masuk & Barang Keluar & Stok Barang \\
\hline T10 & TINTA CANON BCI-24 COLOUR & 133 & 60 & 73 \\
\hline T11 & TINTA CANON 810 XL BLACK & 113 & 63 & 50 \\
\hline T12 & TINTA CANON 811 XL COLOUR & 97 & 54 & 43 \\
\hline T13 & TINTA CANON CL-41 COLOUR & 111 & 45 & 66 \\
\hline T14 & TINTA CANON PG-40 BLACK & 125 & 68 & 57 \\
\hline T15 & TINTA PRINTER WARNA EPSON.S020191 & 80 & 52 & 28 \\
\hline T16 & TINTA PRINTER WARNA T.0854 (YELLOW) & 90 & 44 & 46 \\
\hline T17 & TINTA PRINTER WARNA T.0855 (LIGHT CYAN) & 88 & 35 & 53 \\
\hline T18 & TINTA PRINTER WARNA T.0853 (MAGENTA) & 89 & 33 & 56 \\
\hline T19 & TINTA PRINTER WARNA T.0852 (CYAN) & 88 & 40 & 48 \\
\hline T20 & TINTA PRINTER WARNA EPSON T.039 COLLOUR & 112 & 66 & 46 \\
\hline $\mathrm{T} 21$ & TINTA PRINTER WARNA T0491 (HITAM) & 100 & 57 & 43 \\
\hline $\mathrm{T} 22$ & TINTA PRINTER WARNA T0492 (CYAN) & 97 & 46 & 51 \\
\hline $\mathrm{T} 23$ & TINTA PRINTER WARNA T0493 (MAGENTA) & 97 & 47 & 50 \\
\hline T24 & TINTA PRINTER WARNA T0494 (YELLOW) & 97 & 48 & 49 \\
\hline $\mathrm{T} 25$ & TINTA PRINTER WARNA T0495 (LIGHT CYAN) & 97 & 51 & 46 \\
\hline $\mathrm{T} 26$ & TINTA PRINTER WARNA T0496 (L.MAGENTA) & 97 & 52 & 45 \\
\hline T27 & TINTA PRINTER WARNA HITAM EPSON SO20189 & 128 & 64 & 64 \\
\hline T28 & TINTA PRINTER HP 21 BLACK & 130 & 66 & 64 \\
\hline T29 & TINTA PRINTER HP 60 BLACK & 130 & 59 & 71 \\
\hline $\mathrm{T} 30$ & TINTA PRINTER HP 60 COLOUR & 121 & 62 & 59 \\
\hline T31 & TINTA PRINTER HP 802 BLACK & 115 & 68 & 47 \\
\hline T32 & TINTA PRINTER HP 802 COLLOUR & 99 & 56 & 43 \\
\hline T33 & TINTA PRINTER HP 23(3 COLOUR)EX.PANIN & 90 & 58 & 32 \\
\hline T34 & TINTA PRINTER HP 22 COLOUR & 100 & 44 & 56 \\
\hline T35 & TINTA PRINTER HP 702 BLACK & 120 & 57 & 63 \\
\hline T36 & TINTA WARNA SPITZEN YELLOW & 80 & 50 & 30 \\
\hline T37 & TINTA WARNA SPITZEN BLACK & 110 & 55 & 55 \\
\hline T38 & TINTA WARNA SPITZEN LIGHT CYAN & 90 & 44 & 46 \\
\hline T39 & TINTA WARNA SPITZEN LIGHT MAGENTA & 90 & 50 & 40 \\
\hline $\mathrm{T} 40$ & TINTA WARNA SPITZEN MAGENTA & 90 & 46 & 44 \\
\hline T41 & TINTA WARNA SPITZEN CYAN & 90 & 48 & 42 \\
\hline
\end{tabular}

\subsection{Penentuan Centroid awal}

Dalam penentuan nilai centroid awal dilakukan secara acak pada data pembelian dengan terdiri dari tiga clustering yang akan digunakan untuk perhitungan iterasi ke 1 dan dapat dilihat pada tabel berikut:

Tabel 2. Nilai Centroid Awal

\begin{tabular}{|c|c|c|c|}
\hline Centroid & $\begin{array}{c}\text { Barang } \\
\text { Masuk }\end{array}$ & $\begin{array}{c}\text { Barang } \\
\text { Keluar }\end{array}$ & $\begin{array}{c}\text { Stok } \\
\text { Barang }\end{array}$ \\
\hline C1 & 122 & 70 & 52 \\
\hline C2 & 80 & 52 & 28 \\
\hline C3 & 97 & 48 & 49 \\
\hline
\end{tabular}

\subsection{Perhitungan Jarak Tiap Data ke Pusat Cluster Pada Iterasi Ke-1}

Pengukuran jarak pada ruang jarak (distance space) Euclidean dengan menggunakan rumus dibawah ini (2). Berikut ini merupakan salah satu contoh perhitungan jarak ke pusat cluster dengan menggunakan data T1 pada tabel.1 dan data centroid awal C1pada tabel.2 serta hasilnya ada di JC1 pada tabel.3 sebagai berikut: 


$$
\begin{aligned}
d(1,1) & =\sqrt{(122-100)^{2}+(70-50)^{2}+(52-50)^{2}} \\
& =\sqrt{(22)^{2}+(20)^{2}+(2)^{2}} \\
& =\sqrt{(484+400+4} \\
& =\sqrt{(888} \\
& =29,79933
\end{aligned}
$$

\begin{tabular}{|c|c|c|c|c|c|c|}
\hline \multicolumn{7}{|c|}{ Perhitungan Iterasi Ke-1 } \\
\hline Kode Barang & JC1 & $\mathrm{JC} 2$ & JC3 & $\mathrm{C} 1$ & $\mathrm{C} 2$ & $\mathrm{C} 3$ \\
\hline $\mathrm{T} 1$ & 29.79933 & 29.79933 & 3.741657 & & & $*$ \\
\hline $\mathrm{T} 2$ & 67.18631 & 39.37004 & 34.29286 & & & * \\
\hline $\mathrm{T} 3$ & 58.03447 & 31.1127 & 24.77902 & & & * \\
\hline $\mathrm{T} 4$ & 0 & 51.61395 & 33.43651 & * & & \\
\hline T5 & 34.66987 & 63.51378 & 36.24914 & * & & \\
\hline T6 & 41.08528 & 87.68124 & 74.25631 & $*$ & & \\
\hline $\mathrm{T} 7$ & 15.74802 & 57.4108 & 33.13608 & * & & \\
\hline T8 & 25.72936 & 77.31753 & 57.75812 & * & & \\
\hline T9 & 19.44222 & 40.47221 & 15.93738 & & & * \\
\hline $\mathrm{T} 10$ & 25.72936 & 69.98571 & 44.89989 & $*$ & & \\
\hline T11 & 11.57584 & 41.15823 & 21.9545 & * & & \\
\hline $\mathrm{T} 12$ & 31.01612 & 22.75961 & 8.485281 & & & * \\
\hline $\mathrm{T} 13$ & 30.69202 & 49.53786 & 22.22611 & & & * \\
\hline T14 & 6.164414 & 55.87486 & 35.32704 & $*$ & & \\
\hline $\mathrm{T} 15$ & 51.61395 & 0 & 27.313 & & $*$ & \\
\hline $\mathrm{T} 16$ & 41.66533 & 22.09072 & 8.602325 & & & $*$ \\
\hline T17 & 48.80574 & 31.27299 & 16.30951 & & & $*$ \\
\hline $\mathrm{T} 18$ & 49.73932 & 35.01428 & 18.38478 & & & $*$ \\
\hline $\mathrm{T} 19$ & 45.51923 & 24.65766 & 12.08305 & & & $*$ \\
\hline $\mathrm{T} 20$ & 12.32883 & 39.29377 & 23.62202 & $*$ & & \\
\hline $\mathrm{T} 21$ & 27.09243 & 25.4951 & 11.22497 & & & $*$ \\
\hline $\mathrm{T} 22$ & 34.66987 & 29.22328 & 2.828427 & & & $*$ \\
\hline $\mathrm{T} 23$ & 34.0294 & 28.24889 & 1.414214 & & & $*$ \\
\hline $\mathrm{T} 24$ & 33.43651 & 27.313 & 0 & & & $*$ \\
\hline $\mathrm{T} 25$ & 31.96873 & 24.77902 & 4.242641 & & & $*$ \\
\hline T26 & 31.59114 & 24.04163 & 5.656854 & & & $*$ \\
\hline
\end{tabular}

\subsection{Menempatkan Data ke dalam Pusat Cluster Terdekat}

Setelah dilakukan perhitungan berdasarkan salah satu contoh diatas, maka hasil perhitungan selengkapnya sebagai berikut :

Tabel 3. Hasil Perhitungan Jarak Tiap Data ke Pusat Cluster Pada Iterasi Ke-1

Pengelompokkan Data Pembelian Tinta Dengan K-Means (Susliansyah)|386 
Jurnal Sains Komputer \& Informatika (J-SAKTI)

Volume 3 Nomor 2 September 2019, pp. 381-392

ISSN:2548-9771/EISSN:2549-7200

http://tunasbangsa.ac.id/ejurnal/index.php/jsakti

\begin{tabular}{|l|c|c|c|c|c|c|}
\hline \multicolumn{7}{|c|}{ Perhitungan Iterasi Ke-1 } \\
\hline Kode Barang & JC1 & JC2 & JC3 & C1 & C2 & C3 \\
\hline T27 & 14.69694 & 61.18823 & 37.97368 & $*$ & & \\
\hline T28 & 14.96663 & 63.18228 & 40.47221 & $*$ & & \\
\hline T29 & 23.36664 & 66.31742 & 41.15823 & $*$ & & \\
\hline T30 & 10.67708 & 52.36411 & 29.52965 & $*$ & & \\
\hline T31 & 8.831761 & 42.91853 & 26.98148 & $*$ & & \\
\hline T32 & 28.39014 & 24.53569 & 10.19804 & & & $*$ \\
\hline T33 & 39.59798 & 12.32883 & 20.92845 & & $*$ & \\
\hline T34 & 34.29286 & 35.32704 & 8.602325 & & & $*$ \\
\hline T35 & 17.14643 & 53.38539 & 28.39014 & $*$ & & \\
\hline T36 & 51.45872 & 2.828427 & 25.57342 & & $*$ & \\
\hline T37 & 19.44222 & 40.47221 & 15.93738 & & & $*$ \\
\hline T38 & 41.66533 & 22.09072 & 8.602325 & & & $*$ \\
\hline T39 & 39.59798 & 15.74802 & 11.57584 & & & $*$ \\
\hline T40 & 40.79216 & 19.79899 & 8.831761 & & & $*$ \\
\hline T41 & 40.09988 & 17.66352 & 9.899495 & & & $*$ \\
\hline T42 & 39.59798 & 15.74802 & 11.57584 & & & $*$ \\
\hline
\end{tabular}

Berdasarkan hasil perhitungan jarak pada tabel diatas, setiap data akan menjadi anggota suatu cluster yang memiliki jarak terdekat atau terkecil dari pusat clusternya. Misalnya pada data pertama (T1) nilai yang terkecil ada pada cluster ke-3 dengan hasil perhitungan sebesar 3.741657.

\subsection{Menentukan Centroid Baru dari Hasil Perhitungan Iterasi Ke-1}

Mencari rata-rata dari hasil perhitungan iterasi ke-1 pada setiap Cluster Satu (C1), Cluster Dua (C2) dan Cluster Tiga (C3) untuk menentukan centroid baru dalam melakukan perhitungan iterasi ke-2. Adapun salah satu contoh perhitungan untuk mencari rata-rata pada Cluster Satu (C1) pada attribut B.Masuk sebagai berikut:

$$
\begin{aligned}
& =\frac{122+121+150+124+143+133+113+125+112+128+130+130+121+115+120}{15} \\
& =\frac{1887}{15} \\
& =125,8
\end{aligned}
$$

Tabel 4. Hasil Rata-rata perhitungan untuk Cluster Satu (C1)

\begin{tabular}{|l|r|r|r|}
\hline \multicolumn{4}{|c|}{ Cluster 1 (C1) } \\
\hline $\begin{array}{l}\text { Kode } \\
\text { Brg }\end{array}$ & $\begin{array}{l}\text { B. } \\
\text { Masuk }\end{array}$ & B. Keluar & \multicolumn{1}{c|}{ Stok Brg } \\
\hline T4 & 122 & 70 & 52 \\
\hline T5 & 121 & 45 & 76 \\
\hline
\end{tabular}




\begin{tabular}{|l|r|r|r|}
\hline \multicolumn{4}{|c|}{ Cluster 1 (C1) } \\
\hline $\begin{array}{l}\text { Kode } \\
\text { Brg }\end{array}$ & $\begin{array}{l}\text { B. } \\
\text { Masuk }\end{array}$ & \multicolumn{1}{c|}{ B. Keluar } & \multicolumn{1}{c|}{ Stok Brg } \\
\hline T6 & 150 & 100 & 50 \\
\hline T7 & 124 & 60 & 64 \\
\hline T8 & 143 & 80 & 63 \\
\hline T10 & 133 & 60 & 73 \\
\hline T11 & 113 & 63 & 50 \\
\hline T14 & 125 & 68 & 57 \\
\hline T20 & 112 & 66 & 46 \\
\hline T27 & 128 & 64 & 64 \\
\hline T28 & 130 & 66 & 64 \\
\hline T29 & 130 & 59 & 71 \\
\hline T30 & 121 & 62 & 59 \\
\hline T31 & 115 & 68 & 47 \\
\hline T35 & 120 & 57 & 63 \\
\hline Jml & Jml & Jml & Jml \\
\hline & 1887 & 988 & 899 \\
\hline $\begin{array}{l}\text { Rata- } \\
\text { rata }\end{array}$ & $\mathbf{1 2 5 . 8}$ & $\mathbf{6 5 . 8 6 6 6 7}$ & $\mathbf{5 9 . 9 3 3 3 3}$ \\
\hline
\end{tabular}

Tabel 5. Hasil Rata-rata perhitungan untuk Cluster Dua (C2)

\begin{tabular}{|c|c|c|c|}
\hline \multicolumn{4}{|c|}{ Cluster 2 (C2) } \\
\hline $\begin{array}{l}\text { Kode } \\
\text { Brg }\end{array}$ & B. Masuk & B. Keluar & $\begin{array}{l}\text { Stok } \\
\text { Brg }\end{array}$ \\
\hline T15 & 80 & 52 & 28 \\
\hline T33 & 90 & 58 & 32 \\
\hline T36 & 80 & 50 & 30 \\
\hline Jml & Jml & Jml & Jml \\
\hline 3 & 250 & 160 & 90 \\
\hline $\begin{array}{l}\text { Rata- } \\
\text { rata }\end{array}$ & 83.33333 & 53.33333 & 30 \\
\hline
\end{tabular}

Tabel 6. Hasil Rata-rata perhitungan untuk Cluster Tiga (C3)

\begin{tabular}{|l|r|r|r|}
\hline \multicolumn{4}{|c|}{ Cluster 3 (C3) } \\
\hline $\begin{array}{l}\text { Kode } \\
\text { Brg }\end{array}$ & B. Masuk & B. Keluar & $\begin{array}{l}\text { Stok } \\
\text { Brg }\end{array}$ \\
\hline T1 & 100 & 50 & 50 \\
\hline T2 & 75 & 22 & 53 \\
\hline T3 & 80 & 30 & 50 \\
\hline T9 & 110 & 55 & 55 \\
\hline T12 & 97 & 54 & 43 \\
\hline
\end{tabular}




\begin{tabular}{|l|r|r|r|}
\hline \multicolumn{5}{|c|}{ Cluster 3 (C3) } \\
\hline $\begin{array}{l}\text { Kode } \\
\text { Brg }\end{array}$ & B. Masuk & B. Keluar & \multicolumn{1}{l|}{\begin{tabular}{l} 
Stok \\
\hline T13
\end{tabular}} \\
\hline T16 & 90 & 45 & 66 \\
\hline T17 & 88 & 35 & 46 \\
\hline T18 & 89 & 33 & 53 \\
\hline T19 & 88 & 40 & 48 \\
\hline T21 & 100 & 57 & 43 \\
\hline T22 & 97 & 46 & 51 \\
\hline T23 & 97 & 47 & 50 \\
\hline T24 & 97 & 48 & 49 \\
\hline T25 & 97 & 51 & 46 \\
\hline T26 & 97 & 52 & 45 \\
\hline T32 & 99 & 56 & 43 \\
\hline T34 & 100 & 44 & 56 \\
\hline T37 & 110 & 55 & 55 \\
\hline T38 & 90 & 44 & 46 \\
\hline T39 & 90 & 50 & 40 \\
\hline T40 & 90 & 46 & 44 \\
\hline T41 & 90 & 48 & 42 \\
\hline T42 & 90 & 50 & 40 \\
\hline Jml & Jml & Jml & Jml \\
\hline & 2272 & 1102 & 1170 \\
\hline Rata- & $\mathbf{9 4 . 6 6 6 6 7}$ & $\mathbf{4 5 . 9 1 6 6 7}$ & $\mathbf{4 8 . 7 5}$ \\
\hline rata & & & \\
\hline
\end{tabular}

Dari hasil rata-rata pada tabel diatas dari setiap cluster maka di dapat centroid baru sebagai berikut:

Tabel 7. Centroid Baru

\begin{tabular}{|c|c|c|c|}
\hline CENTROID & $\begin{array}{c}\text { Barang } \\
\text { Masuk }\end{array}$ & $\begin{array}{c}\text { Barang } \\
\text { Keluar }\end{array}$ & $\begin{array}{c}\text { Stok } \\
\text { Barang }\end{array}$ \\
\hline C1 & 125.8 & 65.86667 & 59.93333 \\
\hline C2 & 83.33333 & 53.33333 & 30 \\
\hline C3 & 94.66667 & 45.91667 & 48.75 \\
\hline
\end{tabular}

\subsection{Perhitungan Jarak Tiap Data ke Pusat Cluster Pada Iterasi Ke-2}

Hitung Euclidean distance dari semua data ke titik pusat yang baru pada tabel.7, cara perhitungannya sama seperti yang telah dilakukan pada perhitungan iterasi ke-1. Setelah hasil perhitungan telah diperoleh, maka langkah selanjutnya adalah membandingkan hasil tersebut. Jika hasil posisi 
cluster pada iterasi ke-2 sama dengan posisi iterasi ke-1, maka proses dihentikan, namun jika tidak maka proses dilanjutkan ke iterasi ke-3

Tabel 8. Hasil Perhitungan Jarak Tiap Data ke Pusat Cluster Pada Iterasi Ke-2

\begin{tabular}{|c|c|c|c|c|c|c|}
\hline \multicolumn{7}{|c|}{ Perhitungan Iterasi 2} \\
\hline Kode Barang & JC1 & $\mathrm{JC} 2$ & JC3 & $\mathrm{C} 1$ & $\mathrm{C} 2$ & $\mathrm{C} 3$ \\
\hline $\mathrm{T} 1$ & 31.87573 & 26.24669 & 6.832317 & & & * \\
\hline $\mathrm{T} 2$ & 67.47589 & 39.75201 & 31.25456 & & & * \\
\hline T3 & 59.01465 & 30.91206 & 21.6798 & & & * \\
\hline $\mathrm{T} 4$ & 9.719168 & 47.50672 & 36.57432 & $*$ & & \\
\hline $\mathrm{T} 5$ & 26.7693 & 60.03517 & 37.90577 & $*$ & & \\
\hline T6 & 43.0046 & 83.7987 & 77.38441 & $*$ & & \\
\hline $\mathrm{T} 7$ & 7.361763 & 53.42492 & 35.93532 & $*$ & & \\
\hline T8 & 22.47211 & 73.21354 & 60.83459 & $*$ & & \\
\hline T9 & 19.80056 & 36.59083 & 18.88599 & & & * \\
\hline $\mathrm{T} 10$ & 16.03108 & 66.03198 & 47.49576 & $*$ & & \\
\hline T11 & 16.45384 & 37.06151 & 25.09012 & $*$ & & \\
\hline T12 & 35.45413 & 18.87385 & 10.19055 & & & * \\
\hline $\mathrm{T} 13$ & 26.29187 & 46.16155 & 23.77353 & & & * \\
\hline T14 & 3.714237 & 51.77086 & 38.41676 & $*$ & & \\
\hline T15 & 57.52966 & 4.109609 & 26.12816 & & $*$ & \\
\hline T16 & 44.20327 & 19.68643 & 5.745771 & & & * \\
\hline T17 & 49.2916 & 29.78068 & 13.47889 & & & * \\
\hline $\mathrm{T} 18$ & 49.49676 & 33.48963 & 15.85919 & & & * \\
\hline T19 & 47.33211 & 22.88134 & 8.945048 & & & * \\
\hline $\mathrm{T} 20$ & 19.61111 & 35.18838 & 26.67109 & $*$ & & \\
\hline $\mathrm{T} 21$ & 32.10912 & 21.45279 & 13.57745 & & & * \\
\hline $\mathrm{T} 22$ & 36.10996 & 26.10662 & 3.242513 & & & * \\
\hline $\mathrm{T} 23$ & 35.83381 & 25.03775 & 2.860167 & & & * \\
\hline $\mathrm{T} 24$ & 35.61173 & 24.00463 & 3.138028 & & & * \\
\hline $\mathrm{T} 25$ & 35.27883 & 21.17126 & 6.232754 & & & * \\
\hline T26 & 35.28072 & 20.33607 & 7.517572 & & & * \\
\hline $\mathrm{T} 27$ & 4.986203 & 57.13921 & 40.87396 & $*$ & & \\
\hline $\mathrm{T} 28$ & 5.847697 & 59.11195 & 43.40907 & $*$ & & \\
\hline T29 & 13.68438 & 62.37699 & 43.75706 & * & & \\
\hline T30 & 6.233957 & 48.32069 & 32.51431 & $*$ & & \\
\hline T31 & 16.98418 & 38.81867 & 30.0696 & $*$ & & \\
\hline T32 & 33.20134 & 20.53182 & 12.39007 & & & * \\
\hline T33 & 46.08466 & 8.37987 & 21.17421 & & $*$ & \\
\hline T34 & 34.04794 & 32.26281 & 9.202204 & & & $*$ \\
\hline T35 & 11.03006 & 49.46604 & 31.10756 & $*$ & & \\
\hline
\end{tabular}


Jurnal Sains Komputer \& Informatika (J-SAKTI)

Volume 3 Nomor 2 September 2019, pp. 381-392

ISSN:2548-9771/EISSN:2549-7200

http://tunasbangsa.ac.id/ejurnal/index.php/jsakti

\begin{tabular}{|l|c|c|c|c|c|c|}
\hline \multicolumn{7}{|c|}{ Perhitungan Iterasi 2 } \\
\hline Kode Barang & JC1 & JC2 & JC3 & C1 & C2 & C3 \\
\hline T36 & 56.96837 & 4.714045 & 24.15258 & & $*$ & \\
\hline T37 & 19.80056 & 36.59083 & 18.88599 & & & $*$ \\
\hline T38 & 44.20327 & 19.68643 & 5.745771 & & & $*$ \\
\hline T39 & 43.94006 & 12.47219 & 10.72445 & & & $*$ \\
\hline T40 & 43.93399 & 17.15291 & 6.659371 & & & $*$ \\
\hline T41 & 43.84589 & 14.72715 & 8.466437 & & & $*$ \\
\hline T42 & 43.94006 & 12.47219 & 10.72445 & & & $*$ \\
\hline
\end{tabular}

Karena pada iterasi ke-2 posisi cluster tidak berubah atau sama dengan posisi cluster pada iterasi ke-1 pada tabel.3, maka proses perhitungan iterasi tidak dilanjutkan.

\section{SIMPULAN}

Berdasarkan pembahasan pengelompokkan data pembelian tinta pada PT. Mayer Indah Indonesia, maka kesimpulan yang dapat diambil dari penelitian ini sebagai berikut:

a) Proses pengelompokkan data pembelian tinta dengan menggunakan attribut barang masuk, barang keluar dan stok barang dari jumlah sampel sebanyak 42 dapat dilakukan perhitungan dari iterasi pertama sampai dengan iterasi kedua karena posisi cluster terdekat sudah sama. Dari hasil iterasi ke-2 dapat dikelompokkan barang yang paling banyak keluar pada Cluster 2 (C2) yang terdiri dari 3 barang, untuk barang yang keluarnya sedang ada pada Cluster 1 (C1) dan untuk barang yang sedikit keluarnya ada pada Cluster 3 (C3). Metode $K$ Means dapat digunakan untuk memudahkan bagian pembelian dalam menentukan pengelompokkan data pembelian tinta dengan tepat dan cepat.

b) Untuk penelitian selanjutnya dibuatlah program sistem pendukung keputusan agar lebih mudah mengelola data. Sebaiknya dalam proses pengelompokkan data pembelian tinta digunakan data paling banyak 1 tahun atau sampai 3 tahun, agar bisa lebih akurat. Pada penelitian ini, selain menggunakan metode k-means, dapat juga digunakan metode lain seperti apriori dan Fp Growth atau juga bisa menggunkan metode SPK seperti SAW, AHP dan lain sebagainya.

\section{DAFTAR PUSTAKA}

[1] Metisen, B. M., \& Sari, H. L, "Analisa Clustering Menggunakan Metode K-Means Dalam Pengelompokkan Penjualan Produk Pada Swalayan Fadhila" Jurnal Media Infotama, 11(2), 110-118, 2015.

[2] Muningsih, E., \& Kiswati, S, "Penerapan Metode K-Means Untuk Clustering Produk Online Shop Dalam Penentuan Stok Barang" Jurnal Bianglala Informatika, 3(1), 10-17, 2015. 
Jurnal Sains Komputer \& Informatika (J-SAKTI)

Volume 3 Nomor 2 September 2019, pp. 381-392

ISSN:2548-9771/EISSN:2549-7200

http://tunasbangsa.ac.id/ejurnal/index.php/jsakti

[3] Muflikhah, Lailii, Dian Eka Ratnawati dan Rekyan Regasari Mardi Putri, "Data Mining" Malang: UB Press, 2018.

[4] Tamba, S. P., Kesuma, F. T., \& Feryanto, "Penerapan Data Mining Untuk Menentukan Penjualan Sparepart Toyota Dengan Metode K-Means Clustering" Jurnal Sistem Informasi Ilmu Komputer Prima (JUSIKOM PRIMA), 2(2), 67-72, 2019.

[5] Irwansyah, Edy dan Muhammad Faisal, "Advanced Clustering: Teori Dan Aplikasi" Yogyakarta: Deepublish, 2019. 